Rapp. Gronlands geol. Unders. 58, 49-54 (1973)

\title{
GLACIOLOGICAL OBSERVATIONS IN THE SOUTH-WESTERN SCORESBY SUND REGION \\ A preliminary report
}

\section{Ole B. Olesen and Niels Reeh}

\section{Introduction}

The glaciological work on the 1972 geological expedition to Scoresby Sund, East Greenland, was an expansion of the observations made on the expedition in 1968 (see Olesen \& Reeh, 1969).

In 1968 observations on rate of movement and estimations of the calve-ice production in the northern parts of the Scoresby Sund fjord complex were carried out. A natural continuation of this study was to observe the remainder of the major glaciers, draining the Inland Ice into the southern parts of the same fjord system.

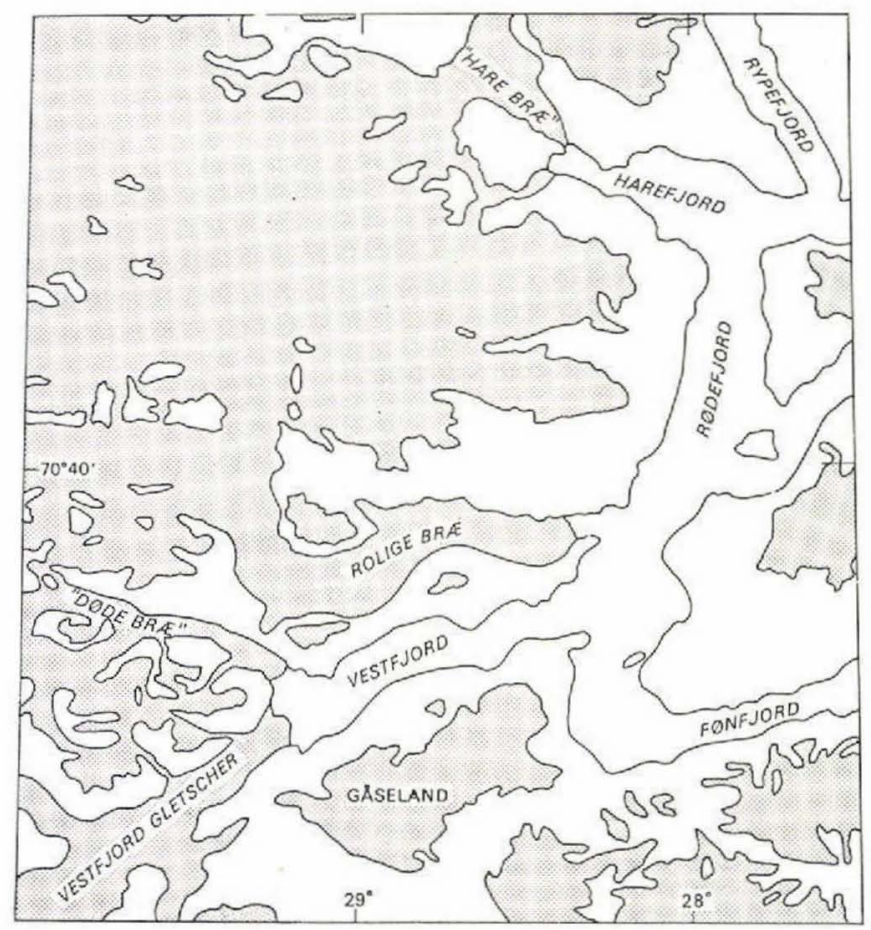

Fig. 7. Sketch map of the south-west part of the Scoresby Sund fjord complex showing the investigated glaciers. 
Thus the glaciological observations were carried out in 1972 on four glaciers, from north to south: 'Hare Bræ', Rolige Bræ, 'Døde Bræ' and Vestfjord Gletscher (see map fig. 7).

At Vestfjord Gletscher continuous observations were carried out in the period July 16th - August 25 th; characteristic points on the glacier surface were surveyed once a day to determine the position, height and flow velocity of the frontal part of the glacier. At the three other glaciers observations were carried out by means of ground-based photogrammetry; three sets of observations were made at approximately fortnightly intervals for the frontal parts of each of the glaciers. Photogrammetrical observations were also used at Vestfjord Gletscher in the area 10 $\mathrm{km}$ from the front and from a short base-line near the front.

\section{Methods of observations}

As mentioned above theodolite measurements were only carried out at Vestfjord Gletscher. The measurements were made with a Zeiss Jena Theo 010 onesecond theodolite, using 'changing face' point by point techniques, and controlling the initial pointing between every five or six points sighted. Both horizontal and vertical angles were observed.

Because natural points on the glacier surface were used the base-line had to be rather short $(383.31 \mathrm{~m})$ in order to facilitate recognition of the points used from both ends of the base-line.

In all 62 points were measured, some for only a few days whereas others were observed for up to 35 days, the discrepancy being due to ablation or collapse of some of the ice peaks used as measuring points.

All base-lines, including those for the photogrammetic observations, were measured using a Zeiss Jena Bala $2 \mathrm{~m}$ subtence bar. As the distances were measured by means of the auxilliary base method the error introduced on the lengths of the base-lines is only of the order of $\pm 0.1 \%$.

The photogrammetric observations were carried out with a Wild P30 phototheodolite with a plate format of $10 \times 15 \mathrm{~cm}$. Altogether 88 exposures were taken comprising 27 different stereoscopic models. The low number of models compared to the number of exposures is due to the fact that at the start and end of the observation period double sets of identical pictures were taken at each station for control purposes.

Bench marks for the photogrammetry were prepared in the form of white squares, about $1 \mathrm{~m}^{2}$ in size, painted with plastic paint on the steep rock walls above the glaciers. These marks stand out clearly on the plates, although small patches of snow still remained in sheltered places at the start of the field season. Wherever possible the positions of the bench marks relative to the photogrammetric stations were measured with the theodolite from longer base-lines than those used for the actual photogrammetry, in order to secure the best possible accuracy. 
Time-lapse photography of the front of Vestfjord Gletscher was carried out with a battery powered Bolex $16 \mathrm{~mm}$ camera capable of shooting single frames. The camera was released by an electric clock every quarter of an hour.

After an initial period of great difficulties the equipment worked well for nearly two weeks, after which the release system failed. During the working period a continuous record of approximately 1300 frames was obtained.

\section{Analysis of observations}

Analysis of the photogrammetric plates of 'Hare Bræ', Rolige Bræ and 'D $\varnothing \mathrm{de}$ Bræ' has been initiated at the Institute of Surveying and Photogrammetry of the Technical University of Denmark. However, calculation of coordinates and velocities of the points measured awaits some modifications of the computer program for photogrammetric calculations.

The theodolite measurements at Vestfjord Gletscher have been analysed by the simple method described below in order to obtain preliminary values of point positions and velocities.

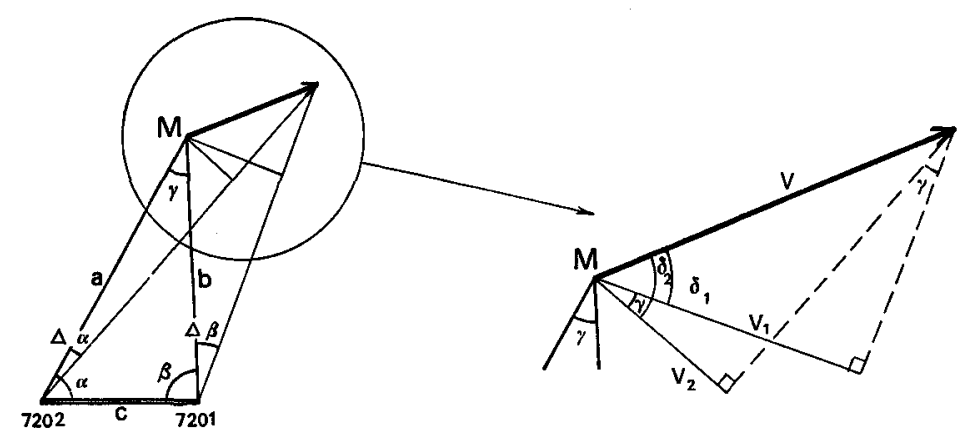

Fig. 8. Diagram showing principle in the preliminary velocity calculations.

From the length of the base-line 7201-7202 and observations at time $t$ of angles $\alpha$ and $\beta$ (fig. 8) distances $a$ and $b$ have been calculated and the position of the measuring point $\mathbf{M}$ has been determined graphically. At some later time $t+\Delta t$, the angles $\alpha$ and $\beta$ have changed by $\Delta a$ and $\Delta \beta$ due to the motion of point $\mathbf{M}$.

Since $\Delta \alpha$ and $\Delta \beta$ are small quantities, the components of the velocity vector $v_{1}$ and $v_{2}$ in directions perpendicular to the lines $a$ and $b$ respectively can be calculated approximately as:

$$
v_{1}=b \Delta \beta / \Delta t \quad \text { and } \quad v_{2}=a \Delta \alpha / \Delta t
$$


Then, neglecting the insignificant changes in the angle $\gamma$ during the motion of point $\mathrm{M}$, the magnitude of the velocity vector can be obtained as:

$$
\begin{aligned}
& v=\frac{1}{\sin \gamma} V\left[\left(v_{1}-v_{2}\right)^{2}+2 v_{1} v_{2}(1-\cos \gamma)\right] \\
& \text { where } \gamma=\pi-(\alpha+\beta)
\end{aligned}
$$

The direction of the velocity vector is determined by the angle $\delta_{1}$ (or equally well $\delta_{2}$ ) (see large scale detail of fig. 8). The angles are given by:

$$
\cos \delta_{1}=v_{1} / v \quad \text { and } \quad \cos \delta_{2}=v_{2} / v
$$

By means of these angles the direction of the velocity vector can be obtained graphically.

\section{Provisional results}

As only data from Vestfjord Gletscher has been treated so far, only results from this glacier will be considered here.

From the map fig. 9 it can be seen that the front has a rather unusual shape. On the south side the ice surface which has a rather gentle slope as far as a point approximately $0.7 \mathrm{~km}$ from the front, abruptly increases the angle of slope terminating in the actual front. On the north side of the glaciers this sudden increase of slope is also very clear, but the front itself is bordered by a low flat lying area. Low-level observations from the air indicate that this area is composed of overturned calve-ice frozen together, so that it forms a kind of 'regenerated glacier'. The same tendency can be traced at the southern margin and it is considered, that before the spring break-up of the fjord ice the situation is very much the same in both places. The dotted line in fig. 9 indicates the position of the front proper at the end of the field season.

The steep slopes at the margins compared to the more gentle sloping middle section is probably due to the glacier being grounded near the confining walls, while there is a deeper trough in the central area where the glacier could be floating.

On fig. 9 the preliminary results of the calculations of positions and rates of movement for some of the observed points have been plotted, the lengths of the arrows being proportional to the rate of movement.

The rate of movement in a cross profile ranges from a minimum of $1.8 \mathrm{~m} / 24 \mathrm{~h}$ near the southern margin $1.3 \mathrm{~km}$ behind the front, to a maximum of $7.0 \mathrm{~m} / 24 \mathrm{~h}$ near the middle of the glacier. This cross section is shown as line A in fig. 9 and 


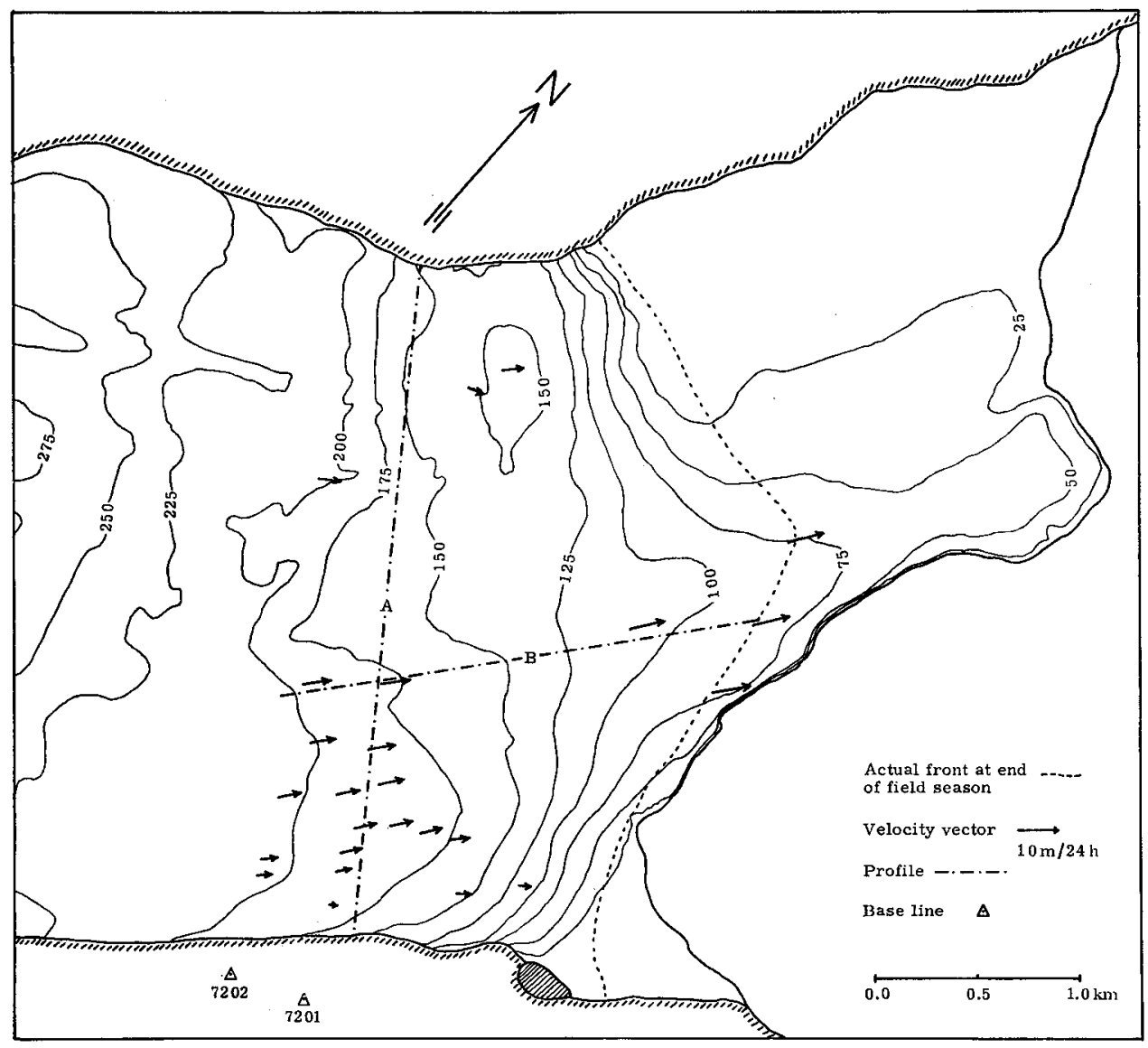

Fig. 9. Map of frontal part of Vestfjord Gletscher showing direction and magnitude of velocities, and the positions of profiles referred to in figs. 10 and 11.

plotted in fig. 10. The velocity profile shows that the rate of movement is somewhat higher in the southern half of the glacier. The mean movement in this profile has been calculated as $4.9 \mathrm{~m} / 24 \mathrm{~h}$.

Along a 'flow-line' (line B in fig. 9 and fig. 11) the spread in the rate of movement varies from $6.4 \mathrm{~m} / 24 \mathrm{~h} 2.2 \mathrm{~km}$ behind the front to $9.2 \mathrm{~m} / 24 \mathrm{~h}$ at the front. From fig. 11 it can be seen that the rate of movement decreases rapidly with distance from the front. 


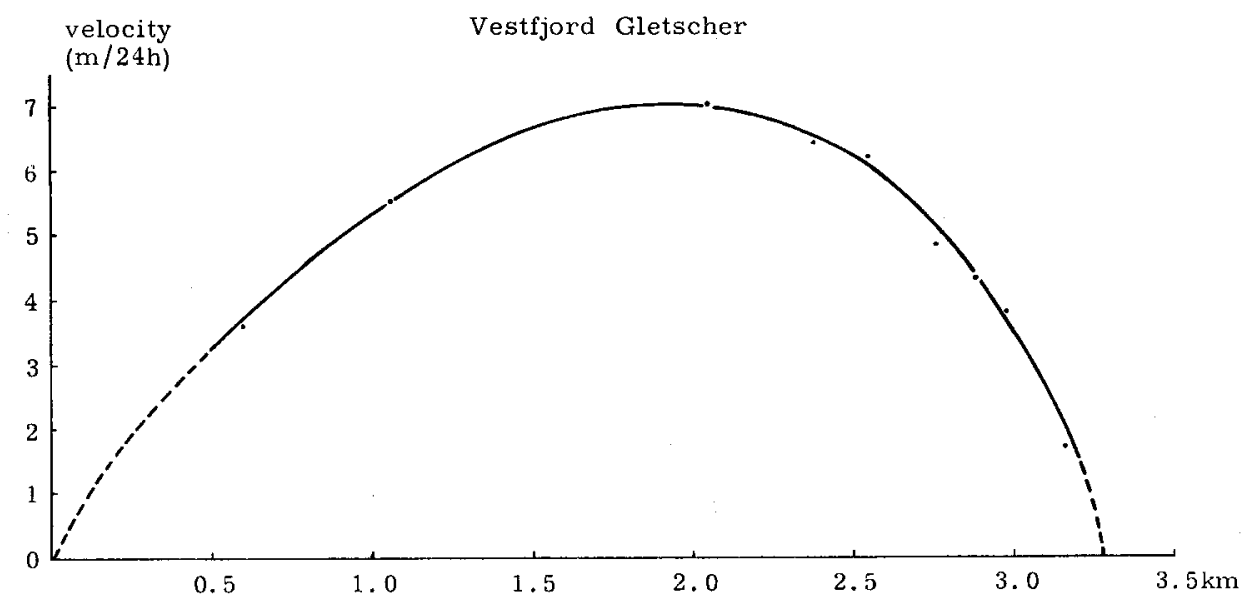

Fig. 10. Surface velocities of Vestfjord Gletscher: cross-section A in fig. 9.

The thickness of the glacier has been estimated as being between 350 and 400 $\mathrm{m}$, based on the height of an upright iceberg lying in front of the glacier. From this figure and the calculated mean movement the ice production of Vestfjord Gletscher is estimated to be in the order of $2.5 \mathrm{~km}^{3}$ per year.

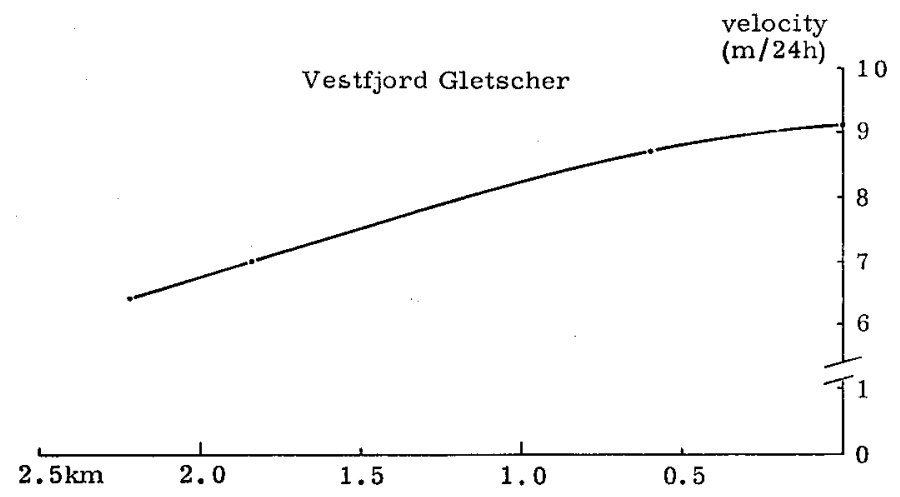

Fig. 11. Surface velocities of Vestfjord Gletscher: longitudinal section in fig. 9.

\section{Reference}

Olesen, O. B. \& Reeh, N. 1969: Preliminary report on glacier observations in Nordvestfjord, East Greenland. Rapp. Grønlands geol. Unders. 21, 41-53. 